\title{
Critical evaluation of computerised $x$ ray planimetry for the measurement of lung volumes
}

\author{
D P S Spence, Y J Kelly, J Ahmed, P M A Calverley, M G Pearson
}

\begin{abstract}
Background - Computerised $x$ ray planimetry has been advocated as an alternative to body plethysmography and helium dilution for measuring static lung volumes. The accuracy and reproducibility of this method has been assessed in comparison with these standard methods. Methods - Plethysmographic and planimetric measurements of total lung capacity (TLC) and functional residual capacity (FRC) were made in 10 normal subjects and in 12 patients with chronic obstructive pulmonary disease (COPD), with additional helium dilution measurements in the latter 12 patients.

Results - Mean lung volumes (TLC and FRC) for groups of subjects measured by planimetry and by plethysmography were similar in both groups and larger than the helium dilution measurement in patients with COPD. Intraindividual agreement between planimetry and plethysmography was poor, however, with a wide confidence interval $(-2 \cdot 2$ to $+2 \cdot 31)$. The planimeter did not measure reliably changes in volume from TLC to FRC in individuals.

Conclusions - Mean lung volumes measured by planimetry in a group of patients probably reflect a regression to the mean of the computer algorithm rather than accurate TLC estimation. The technique is not yet robust enough to replace the established techniques of helium dilution or plethysmography.

(Thorax 1995;50:383-386)
\end{abstract}

Keywords: $x$ ray planimetry, plethysmography, helium dilution, lung volumes.

Aintree Chest Centre, Liverperley Hospital

UK

D P S Spence

P M A Calverley

M G Pearson

Department of

Biological Sciences,

University of Salford, Salford M6 6PU,

UK

Y J Kelly

$\mathrm{J}$ Ahmed

Reprint requests to: Dr M G Pearson.

Received 21 March 1994 Returned to authors 11 May 1994

Revised version received 16 November 1994 Accepted for publication 13 December 1994 with chronic obstructive pulmonary dise (COPD) of overcoming the artefactual errors caused by prolonged time constants for gas mixing and pressure equilibration that can confound both helium dilution and plethysmographic techniques. ${ }^{8-11}$ Radiographic lung volume estimation could save a visit to the respiratory laboratory, is inexpensive, and has been used in recently published epidemiological studies. ${ }^{12}$ Such practical advantages are only of value, however, if the radiographic measurements are both reliable and well validated against more established techniques. Limited data are available on earlier radiographic techniques but none concerning the computerised planimeter.

We have evaluated the planimetric technique in both normal individuals and in patients with COPD and have examined (1) whether the planimetric lung volume measurements can be measured reproducibly by different observers; (2) if radiographic lung volumes are comparable with the helium dilution and plethysmographic values; (3) whether the radiographic method can accurately detect changes in lung volume; and (4) if the posture adopted for the chest radiograph affects the results.

\section{Methods}

PATIENTS

Ten healthy male volunteers (mean age 33 (3) years) were recruited from the hospital staff and 12 patients (nine men) with a diagnosis of COPD $^{13}$ were recruited from the outpatient clinic (table 1). Written informed consent was obtained from all subjects and the study was approved by the district ethical committee.

\section{PROTOCOL}

Posteroanterior and lateral chest radiographs were taken with the subject seated to be comparable with the plethysmographic and helium dilution methods. Ventilation was monitored during the procedure by having the subject rebreathe from a water sealed spirometer (PK Morgan Ltd) incorporating a $\mathrm{CO}_{2}$ absorber. Oxygen was added to the system to maintain a constant volume of gas within the apparatus.

Table 1 Mean (SD) demographic data on all subjects

\begin{tabular}{lcc}
\hline & $\begin{array}{l}\text { Normal volunteers } \\
(n=10)\end{array}$ & $\begin{array}{l}\text { COPD patients } \\
(n=12)\end{array}$ \\
\hline Age (years) & $32 \cdot 7(2 \cdot 7)$ & $61 \cdot 8(3 \cdot 3)$ \\
FEV $_{1}(1)$ & $4 \cdot 87(0 \cdot 4)$ & $0 \cdot 84(0 \cdot 07)$ \\
FEV $_{1}(\%$ predicted) & $102(3)$ & $28(8)$ \\
FRC (1)* $_{\text {TLC (1)* }}$ & $3 \cdot 6(0 \cdot 85)$ & $6 \cdot 33(0 \cdot 29)$ \\
\hline
\end{tabular}

$\mathrm{FEV}_{1}=$ forced expiratory volume in one second; $\mathrm{FRC}=$ functional residual capacity; TLC $=$ total lung capacity; $\mathrm{COPD}=$ chronic obstructive lung disease.

* Measured by body plethysmography. 
Figure 1 Outlines on (A) the posteroanterior and (B) the lateral chest planimeter to construct an image of the lungs and associated structures. radiographs used by the
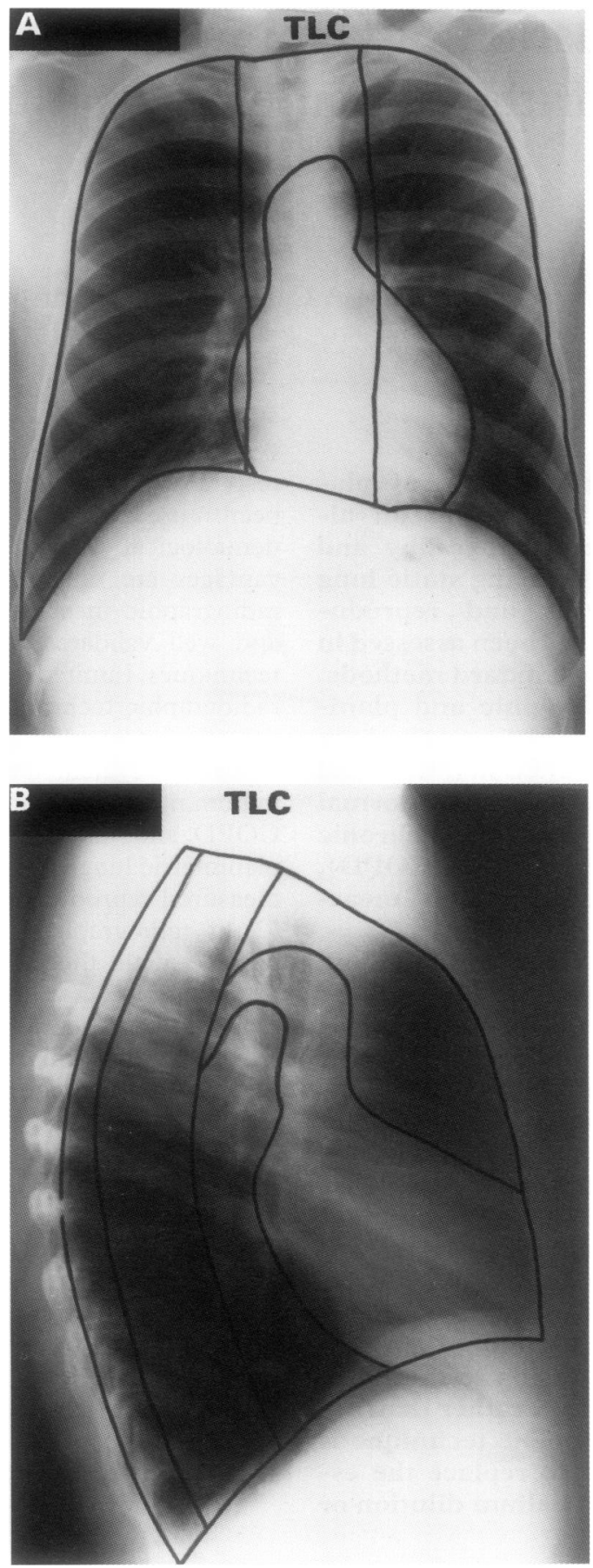

Table 2 Mean (SD) values for TLC and FRC in normal subjects and patients with COPD, and $95 \%$ CI of agreement between different measures

\begin{tabular}{|c|c|c|c|c|}
\hline & $\begin{array}{l}\text { Mean } \\
T L C(l)\end{array}$ & $\begin{array}{l}95 \% \text { CI for an } \\
\text { individual value }\end{array}$ & $\begin{array}{l}\text { Mean } \\
\text { FRC (l) }\end{array}$ & $\begin{array}{l}95 \% \text { CI for an } \\
\text { individual value }\end{array}$ \\
\hline $\begin{array}{l}\text { Normal subjects }(n=10) \\
x \text { ray planimetry }\end{array}$ & $7 \cdot 13(1.02))$ & \multirow[b]{2}{*}{$-2 \cdot 19$ to $+2 \cdot 29$} & $4.62(0.85))$ & \multirow[b]{2}{*}{-0.06 to $+2 \cdot 10$} \\
\hline $\begin{array}{l}\text { Body plethysmography } \\
\text { (seated) } \\
\text { Body plethysmography } \\
\text { (arms raised) }\end{array}$ & $7 \cdot 08(1 \cdot 12)\}$ & & $3.60(1.01)\}$ & \\
\hline \multicolumn{5}{|l|}{$\begin{array}{l}\text { COPD subjects }(n=12) \\
x \text { ray planimetry }\end{array}$} \\
\hline Observer 2 & & -0.67 to +0.67 & $6 \cdot 27(1 \cdot 59)\}$ & -0.39 to +0.57 \\
\hline $\begin{array}{l}\text { Body plethysmography } \\
\text { (seated) } \\
\text { Helium dilution }\end{array}$ & $\left.\begin{array}{l}7 \cdot 68(1 \cdot 24) \\
6 \cdot 60(1 \cdot 10)\end{array}\right\}$ & $-2 \cdot 40$ to 1.52 & $\left.\begin{array}{l}6.33(0.99) \\
4.95(0 \cdot 86)\end{array}\right\}$ & -2.42 to +2.12 \\
\hline
\end{tabular}

$\mathrm{TLC}=$ total lung capacity; $\mathrm{FRC}=$ functional residual capacity; $\mathrm{COPD}=$ chronic obstructive pulmonary disease.
Respiration was monitored by watching the water sealed spirometer. Subjects were instructed to breathe in fully until a plateau was observed on the spirometric trace, at which point the posteroanterior radiograph at total lung capacity (TLC) was taken. Subjects were then told to relax and breathe normally and, after a few breaths, the functional residual capacity (FRC) posteroanterior radiograph was taken, the breath being held at end tidal lung lung volume as judged from the spirometer. The procedure was repeated to obtain a pair of lateral chest radiographs. The distance from $x$ ray tube to film was six feet throughout.

\section{PLANIMETRIC LUNG VOLUMES}

In the normal volunteers planimetric $x$ ray lung volumes were determined by a single observer (DS). In the patients with COPD lung volumes were independently determined from the same pairs of radiographs by DS and a second observer (YJK).

Briefly, the measurement procedure comprises tracing the pleural outline and those of the other intrathoracic structures (fig 1). The posteroanterior and lateral radiographs are aligned using the arch of the aorta as a common reference point. The computer program then divides the resulting shapes into 200 slices, calculates the volume of each slice and, thus, the total chest volume. From this the volumes of the heart, great vessels, subdiaphragmatic region, and spine (including paravertebral musculature) are subtracted to leave the total lung volume. A correction factor is applied to this total lung volume to take account of solid tissue and volume of blood within the lungs. The net result is the calculated volume of air within the lungs.

CONVENTIONAL LUNG VOLUME MEASUREMENTS

Lung volumes were measured in a constant volume body plethysmograph (PK Morgan Ltd) with the subject panting at $1 \mathrm{~Hz} .{ }^{9}$ In both the normal volunteers and patients measurements were made whilst supporting the cheeks with the hands, and in the normal subjects additional measurements were made with the arms raised to mimic the position adopted for the lateral radiograph. In the patients lung volumes were also measured by the standard rebreathing helium dilution technique.

\section{STATISTICAL ANALYSIS}

Data are expressed as mean (SD) unless otherwise stated. Comparisons between measurement techniques were evaluated using the methods recommended by Bland and Altman ${ }^{14}$ with $95 \%$ confidence intervals (CI). For comparison with previously published work on $x$ ray planimetry these results were compared with simple linear regression analysis.

\section{REPRODUCIBILITY OF CONVENTIONAL} MEASUREMENTS

The reproducibility of body plethysmography and of helium dilution lung volumes in our 
Figure 2 Total lung volumes (TLC) of all subjects when compared by (A) linear regression and (B) by the more appropriate Bland and Altman approach which plots the difference between plethysmography and planimetry results against the mean value of the two techniques for each individual.
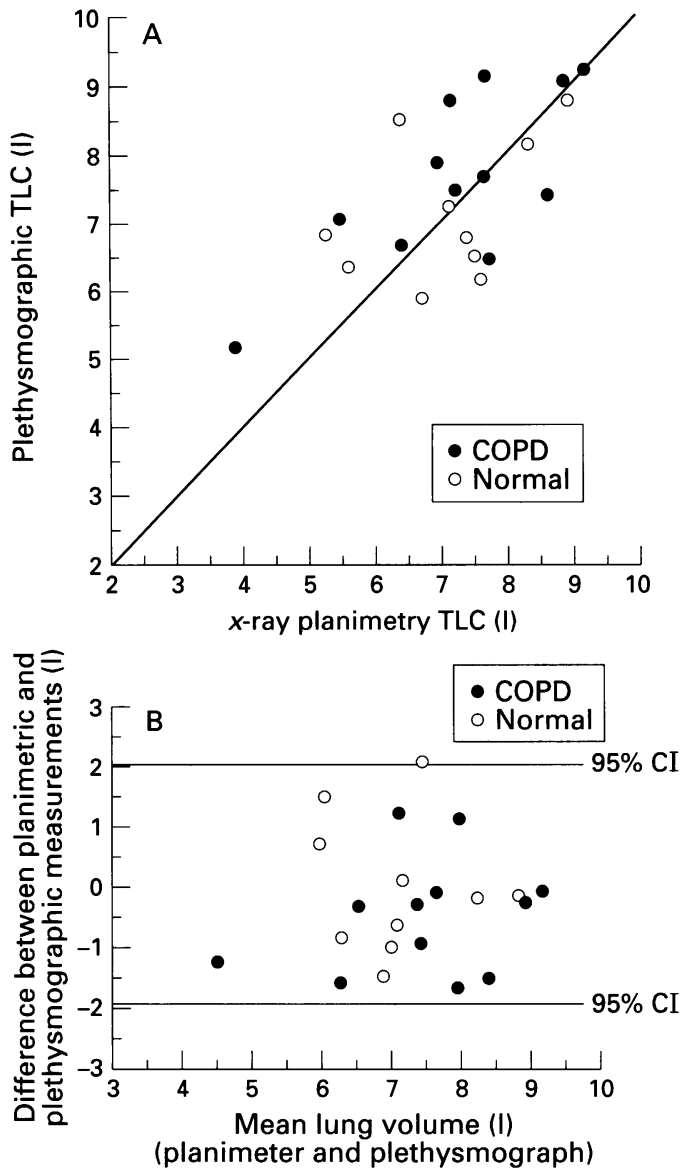

laboratory have been assessed in a separate study of 32 patients with COPD of similar severity (age 62.5 (7.5) years, $\mathrm{FEV}_{1} 0.77$ $(0 \cdot 24) 1)$, each studied on four occasions. ${ }^{15}$ The coefficient of variation for both techniques was less than $5 \%$, yielding a confidence interval for an individual measurement by body plethysmography of 0.31 to 0.421 .

\section{Results}

NORMAL VOLUNTEERS (table 2)

Mean TLC values measured by plethysmography and by $x$ ray planimetry were similar for the whole group. However, the Bland and Altman approach showed that there was poor concordance within individual subjects such that the differences had a $95 \% \mathrm{CI}$ of $-2 \cdot 19$ to +2.291 (fig 2). Mean FRC measured with the planimeter was higher than with the plethysmograph, but again the $95 \%$ CI of differences within individuals was wide $(-0.06$ to $+2 \cdot 71$ ).

The mean inspiratory capacity from FRC to TLC measured on the spirometer was similar to that derived from differences in radiographs at FRC and TLC (2.88 $(0.34)$ 1), but again there were considerable discrepancies within individuals $(95 \% \mathrm{CI}$ of difference in techniques $-1 \cdot 75$ to $+2 \cdot 491)$.

Effect of posture on plethysmographic lung volume measurements

Raising the arms into the position used for a lateral chest radiograph resulted in a higher plethysmographic value for TLC $(7 \cdot 3(1 \cdot 0) v$ $7 \cdot 1(1 \cdot 1) 1)$ and FRC (4.0 (0.9) v $3.6(0.9) 1$, $\mathrm{p}<0.05)$ compared with the conventional position with the arms by the side.

PATIENTS WITH COPD

Measurements of lung volume by different observers from the same pair of radiographs agreed more closely than for comparisons between the techniques (table 2). The mean TLC and FRC values for the whole group were similar when measured by $x$ ray planimetry and by plethysmography, and both were larger than volumes measured by helium dilution (both $\mathrm{p}<0 \cdot 05)$. Again the $95 \%$ confidence limits for agreement within an individual were wide when the radiographic technique was compared with either plethysmography or helium dilution. The plethysmography and helium measurements had smaller $95 \%$ confidence intervals of agreement despite differing mean values. Inspiratory capacity measured by plethysmography was $1.06(0.83) 1$ and $1.18(0.28) 1$ by $x$ ray planimetry. The mean difference was 0.121 but with a $95 \%$ CI of $-1 \cdot 45^{10}$ to $+1 \cdot 731$.

\section{Discussion}

All biological measurements have an inherent variability and, to interpret a result in an individual patient, the degree of confidence which can be placed on a given value must be known. Measurements of lung volume by helium dilution and by body plethysmography have been used for many years and have a coefficient of variation of between $5 \%$ and $10 \% .{ }^{1516}$ In our laboratory we have found a coefficient of variation for repeated measurements on separate days in patients with COPD of less than $5 \%$ for both techniques $(95 \% \mathrm{CI} \pm 0 \cdot 61) .{ }^{16}$ Moreover, both helium dilution and plethysmographic measurements are supported by an extensive amount of literature which shows that the data they yield are clinically reproducible and able to detect reliably the changes in lung function resulting from disease or treatment.

We have shown that the mean lung volume for two groups of subjects, with and without COPD, are similar whether measured by plethysmography, helium dilution, or by $x$ ray planimetry. In previous studies the individual data have been plotted on an $x-y$ plot and a linear regression performed to assess reproducibility. Our data treated in this way yield a linear regression correlation coefficient $(r)$ of 0.85 which is very similar to previous work. ${ }^{1718}$ It is therefore tempting to argue that the method has been validated since mean values agree and individual values are significantly correlated.

However, the statistical validity of this approach has been challenged as it does not compare the repeatability of the measurement alone, but reflects other factors such as body size. Tall people will tend to have larger lung volumes than small people no matter what technique is used. If the subject group includes both tall and short people then a simple $x-y$ plot and linear regression will inevitably appear to correlate well because of the relationship of 
volume to height. Intertest differences therefore cannot be assessed by linear regression. Bland and Altman showed how the intraindividual differences between measurement techniques should be assessed and, when applied to our data, this method shows a very wide $95 \%$ CI for individuals. Thus, for TLC it indicates that, if the first value is known, the second technique had a $95 \%$ chance of being within $2 \cdot 21$ of the first.

The internal reproducibility of the $x$ ray planimetry measurement as recorded by two different observers on the same pair of radiographs was good, suggesting that the mechanical aspects of the planimeter and translation of radiograph to computer is not a problem.

Plethysmographic values are known to be consistently larger than helium dilution values for good physiological reasons and, not surprisingly, our results in patients with COPD confirmed this.

The concordance of mean values between $x$ ray planimetry and other techniques probably reflects the fact that the algorithm is showing a regression to the mean that hides individual variation. For individuals there are a number of possible explanations for the poor concordance with other techniques. The radiographic exposure will vary with the radiographer, and a different grey scale will result in different lung outlines being defined. Thus, planimetry volumes measured by two observers from the same radiograph agree more closely than does planimetry with other techniques. Secondly, the computer algorithm makes a number of assumptions about the geometry of the chest. It cannot correct for individuals of different shape or for the change in shape that accompanies either a change in volume or change due to disease. Thirdly, the computer assumes that a patient has breathed in to TLC when the radiograph was taken. Some patients, for varying reasons, find it difficult to comply with simple commands and the radiographer has no method of checking that full inspiration has occurred.

The radiographic technique algorithms were derived to measure TLC. It is important for a measurement technique to be able to record changes in volume that occur as physiology and anatomy alter with disease states. The planimeter was not sufficiently sensitive to record reliably changes in volume between TLC and FRC compared with a spirometer. The wide confidence interval for agreement within an individual must throw doubt on the ability of planimetry to measure accurately or reliably change due to disease. Previous studies ${ }^{1-71718}$ used less sophisticated methods of calculating volume from radiographs, relying on as few as five measurements from the paired films. It is likely that these simple systems will be even more prone to error.

Lastly, with the use of the body plethysmograph, we showed that raising the arm position to mimic the position for a lateral chest radiograph results in a small but significant increase of 0.251 in TLC which means that posteroanterior and lateral radiographs are actually being recorded at different values of TLC, which is a further complication for a computer algorithm.

In conclusion, radiographic estimation of lung volume may have theoretical advantages, especially in patients with airflow limitation, but when the method is critically assessed with the appropriate statistical technique the values in individuals are not comparable to established techniques. The variability within an individual is too large to be clinically useful. Moreover, the inability to detect accurately change in volume within the same person suggests that the radiographic measurement may not be a reliable indicator of either worsening disease or of a response to treatment. Even its value in following changes in group mean data cannot be assumed until it is compared with standard techniques in the same population over months or years. Until the method has been shown to reflect reliably within-patient changes resulting from disease or treatment, there must be some 을 doubt as to whether it is valid for use as part $\rightarrow$ of epidemiological surveys. The planimeter it- $\frac{7}{0}$ self is easy to use and internally reproducible, but the computer algorithm needs further re- $\vec{c}$ finement to make it clinically relevant.

1 Hurtado A, Fray WH. Studies of total lung capacity and its subdivisions. $\mathcal{F}$ Clin Invest 1933;12:807-23.

2 Kovach JC, Avedian V, Morates G, Poulos P. Lung compartment determination. $\mathcal{F}$ Thorac Surg 1956;31:452-7.

3 Bernhard HJ, Pierce JA, Joyce JW, Bates JH. Roentgenographic determination of TLC. A new method evaluated in health, emphysema and congestive cardiac failure. Am f Med 1960;28:51-60.

4 Pratt PC, Klugh GA. A method for the determination of total lung capacity from posteroanterior and lateral chest roentograms. Am Rev Respir Dis 1967;96:548.

5 Harris TR, Pratt PC, Kilburn KH, Total lung capacit measured by roentograms. Am $\mathcal{F}$ Med 1971;50:756-63.

6 Loyd HM, String TS, Dubois AB. Radiographic and plethysmographic determination of total lung capacity. Radiology 1966;86:7-14.

7 Pierce RJ, Brown DJ, Holmes M, Cumming C, Denison DM. Estimation of lung volumes from chest radiographs using shape information. Thorax 1979;34:725-34.

8 Rodenstein DO, Stanescu DC. Reassessment of lung volume measurement by helium dilution and by body plethysmography in chronic airflow obstruction. Am Rev 윽 thysmography in chronic ai

Respir Dis 1982;126:1040-4.
9 Rodenstein DO, Stanescu DC. Frequency dependence of $\frac{D}{O}$ plethysmographic volume in healthy and asthmatic subjects. F Appl Physiol 1983;54:159-63.

10 Rodenstein DO, Stanescu DC, Francis C. Demonstration 0 of failure of body plethysmography in airway obstruction. f Appl Physiol 1982;52:949-54.

11 Stanescu DC, Rodenstein D, Cauberghs M, Van de Woestijne KP. Failure of body plethysmography in bronchial asthma. $\mathcal{f}$ Appl Physiol 1982;52:939-48.

12 Kilburn KH, Warshaw RH, Thornton JC, Thornton K, Miller A. Predictive equations for total lung capacity and residual volume calculated from radiographs in a ran- $\mathbb{D}$ and residual volume calculated from radiographs in a ran519-23.

13 American Thoracic Society. Epidemiology standardisation project. Am Rev Respir Dis 1978;118:55-88.

14 Bland JM, Altman DG. Statistical methods for assessing agreement between two methods of clinical measurement. Lancet 1986; i:307-10.

15 Spence DPS. MD Thesis, University of Leicester, 1993.

16 DuBois AB, Botello SY, Bedell GN, Marshall R, Comroe $\mathrm{JH}$. A rapid plethysmographic method for measuring thoracic gas volume. A comparison with the nitrogen washout acic gas forme. A compan function residual capacity in normethod for measuring functional residual cap.

17 O'Shee J, Lapp NL, Russakoff AD, Reger R, Morgan WKC. 을 Determination of lung volumes from chest films. Thorax 1970;25:544-9.

18 Reger RB, Young A, Morgan WKC. An accurate and rapid radiographic method of totalling total lung capacity. Thorax 1972;27:163-8. 